\title{
TÉCNICAS de MANUTENÇÃo EM LINHAS DE TRANSMISSÃo dE ENERGIA
}

\section{RESUMO}

A manutenção das linhas de transporte e distribuição de energia eléctrica é um serviço fundamental prestado pelas empresas de transporte e distribuição. A aplicação de técnicas eficientes na actividade de manutenção das linhas, define a qualidade de serviço prestado pelas empresas. Indicadores como o tempo e número de intervenções para restabelecer as condições normais de funcionamento, são reveladores da qualidade de serviço prestado por essas empresas que, no caso de incumprimento das regras estabelecidas no Regulamento da Qualidade de Serviço, podem implicar em elevados prejuízos.

A disponibilidade de informação apropriada ao pessoal técnico torna-se essencial e contribui para uma maior eficácia dos serviços de manutenção, tanto ao nível da manutenção correctiva como na manutenção preventiva.

Este trabalho descreve a aplicação de duas técnicas modernas na manutenção das linhas eléctricas que, além de incrementarem a segurança e a fiabilidade do sistema eléctrico, garantem uma melhoria dos dados quantitativos fornecidos às equipas de manutenção .

\section{INTRODUÇÃO}

A segurança e fiabilidade do sistema eléctrico estão fortemente relacionadas com o bom funcionamento das linhas de transmissão.

Enquanto as centrais de produção, subestações primárias e de distribuição possuem controlo e monitorização com tecnologias avançadas, como sistemas computadorizados e SCADA (Supervisory Control And Data Acquisition), a protecção principal e as informações para manutenção das linhas de transmissão são baseadas nos dados fornecidos por relés ou oscilógrafos.

Apesar de estes dispositivos serem extremamente fiáveis e eficientes no âmbito da protecção, os relés apenas fornecem informações qualitativas, e dificilmente fornecem informações quantitativas relevantes para a execução dos trabalhos de manutenção. Os dados fornecidos por oscilógrafos dependem de complexas análises que podem levar horas ou mesmo dias, e geralmente não possuem a precisão adequada para as equipas de campo.

Assim sendo, para a melhoria da segurança e o aumento da fiabilidade do sistema eléctrico, é imprescindível o desenvolvimento de soluções que melhorem os dados quantitativos fornecidos às equipas de manutenção, tanto correctiva como preventiva. Este trabalho apresenta e analisa os benefícios de duas técnicas modernas de manutenção em linhas de transmissão que vêm ao encontro das necessidades expostas.

A primeira técnica descrita, aplicada nos serviços de manutenção correctiva, é a localização de falhas em linhas transmissão através do princípio das ondas viajantes.

Trata-se de uma configuração simples, capaz de localizar defeitos fase-terra e identificar as secções afectadas com grande precisão e rapidez, trazendo assim informação preciosa para os serviços de manutenção correctiva.

A segunda tecnologia apresentada é a detecção de corrosão nos condutores em linhas de transmissão aéreas, com aplicação nas actividades de manutenção preventiva. 0 sistema pode funcionar com a linha activa e efectua o diagnóstico das condições de corrosão dos cabos condutores, incluindo as partes internas, permitindo desta forma que as equipas de manutenção actuem preventivamente evitando acidentes e a interrupção do fornecimento de energia. Esta técnica tem uma aplicação intensiva em ambientes agressivos como zonas litorais ou com incidência de chuva ácida (zonas industriais).

\section{LOCALIZADOR DE DEFEITOS POR ONDAS VIAJANTES}

\subsection{Princí́to de funcionamento}

$\mathrm{Na}$ ocorrência duma falha numa linha de transmissão radial, surge um surto de corrente induzindo ondas electromagnéticas que se propagam nas três fases por toda extensão da linha. 
A localização do ponto de defeito consiste em detectar a diferença de tempo que essas ondas viajantes levam para chegar aos seus extremos.

Este princípio está representado na figura 1.

\section{a) TIPOS DE CASAS INTELIGENTES}

De facto, há problemas com a conceptualização da "casa inteligente"! Parece haver pouca concordância sobre como uma casa inteligente deve ser e sobre que tecnologias ela deve incorporar.

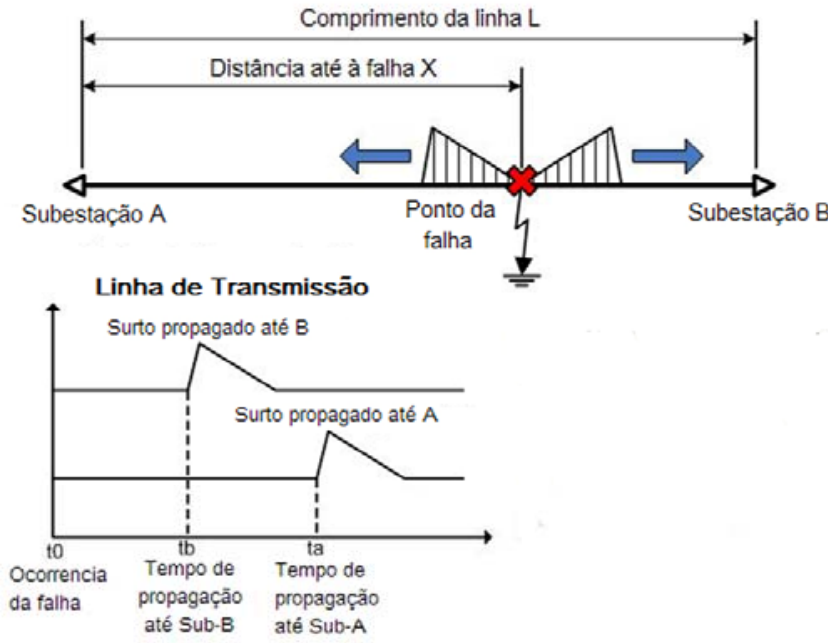

Figura 1 - Principio das ondas viajantes

O comprimento da linha $L$ e a velocidade de propagação do surto $v$ fazem parte dos aspectos construtivos da linha, são valores conhecidos. Medindo a diferença de tempo entre a chegada das ondas aos pontos A (início da linha) e B (final da linha) é possível calcular a localização exacta da falha, através do cálculo do valor de $X$ :

$$
\mathrm{X}=\frac{\mathrm{L}}{2}+\frac{\left(\mathrm{t}_{\mathrm{a}} \cdot \mathrm{t}_{\mathrm{b}}\right) . \mathrm{N}}{2}
$$

\subsection{LOCALIZAÇÃO POR SISTEMA GPS}

Um localizador de defeitos por ondas viajantes basicamente é composto por um ou mais pares de estações locais, sensores de campo magnético e antenas GPS (Global Positioning System) ligados entre si e com a estação principal, conforme mostra a fig. 2. e antecipando as acções a tomar ("the aware home").

\section{b) AS FUnÇ̃̃ES DA CASA INTELIGENTE}

Actualmente as habitações podem estar equipadas com sistemas que associam diversas funcionalidades nas áreas de segurança, conforto, gestão de energia e comunicações. Funcionalidades principais: detecção de incêndio, intrusão, fuga de água ou gás, avisos, comandos e controlo remotos, "Anything, Anytime, Anywere".

As capacidades da domótica podem ser um auxiliar precioso para contornar as dificuldades temporárias ou permanentes, físicas ou mentais do ser humano. Além disso, estes sistemas permitem facilitar as tarefas a idosos que assim vêem minimizados algumas limitações a que estão expostos.

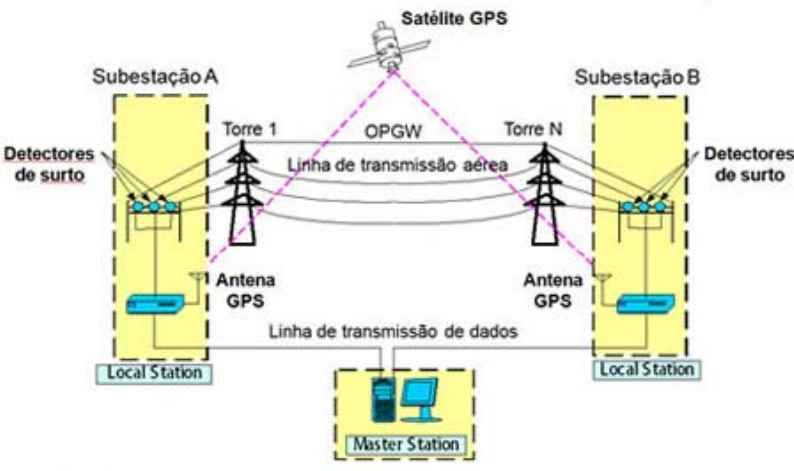

Figura 2 - Visão geral de um localizador de defeitos por ondas viajantes

Pela análise da equação (1), concluímos que a precisão da medida de tempo está directamente relacionada com a localização exacta da falha. Por isso, os sistemas de localização de defeitos por ondas viajantes utilizam as informações de tempo dos satélites do GPS para manter a precisão necessária dos seus contadores e sincronizar os relógios das estações locais.

Assim, cada estação local de um sistema localizador de defeitos por ondas viajantes recebe dados dos satélites para a sincronização dos seus contadores, através de uma antena e receptor GPS. Ao utilizar o GPS é possível manter uma contagem de tempo de alta definição com imprecisão menor que $1 \mu \mathrm{s}$, permitindo uma localização de defeitos com incerteza menor que 300 metros, mesmo em linhas com compensação série. 
Também na estação local, um processador de sinais recebe as informações dos sensores de campo magnético instalados nas fases. Na ocorrência de uma falha, armazena-se o valor dos contadores e envia-se um sinal de informação para a estação principal.

Nesse momento, a estação principal confirma o sinal de informação da estação local e armazena os dados do surto, com os quais o software de análise fará o cálculo da distância. Este software de análise também deve ter em consideração as deformações da onda de surto durante a sua propagação para melhorar a precisão do cálculo.

Para isso, é comum que se execute um processo de compensação dessa distorção que é baseado na correcção da forma de onda do surto recebida das estações locais.

No final do processo, a estação principal indica a distância e o ponto de referência mais próximo do defeito, bem como a oscilografia da corrente de sequência zero da falha, através da qual é possível identificar o tipo de defeito.

\section{Detector de Corrosão em Cabos Condutores}

\subsection{PRINCíPIO DE FUNCIONAMENTO}

O funcionamento do detector de corrosão em cabos condutores é relativamente simples, baseando-se no princípio das correntes de Foucault e numa ponte de indutâncias.

As correntes de Foucault são um fenómeno eléctrico que ocorre quando um campo magnético variável intercepta um material condutor fixo ou vice-versa. O movimento relativo causa uma corrente de circulação no condutor, que segundo a Lei de Lenz gera um campo magnético que se opõe ao efeito do campo aplicado. Quanto maior for a condutividade do condutor, mais forte for o campo magnético aplicado ou mais rápido for o movimento relativo, maior será a corrente gerada e consequentemente maior o campo que se opõe. Conforme mostra o esquema da figura 3 , ao aplicar um campo magnético paralelo ao condutor que possui uma velocidade $v$ conhecida, é gerada uma corrente de Foucault marginal ao condutor, que induz um campo magnético oposto ao aplicado e que pode ser medido utilizando uma bobina activa $Z^{\prime}$.

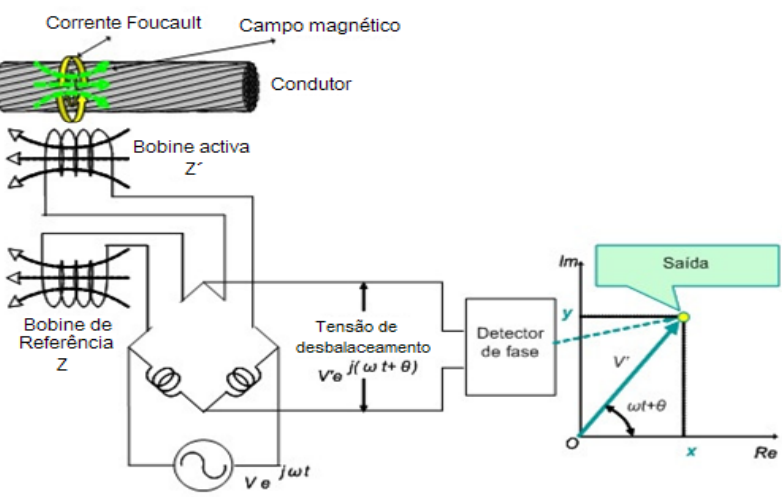

Figura 3 - Princípio de funcionamento do detector de corrosão

As bobines $Z$ e Z' estão interligadas em forma de ponte de indutâncias como mostra a figura 3, na bobine $Z$ é colocada uma amostra do cabo original funcionando esta como referência.

Aos terminais da ponte surge uma tensão de desbalanceamento cujo a magnitude dessa tensão é directamente proporcional à secção do cabo condutor avaliado, já que quanto pior o estado de corrosão do mesmo, menor será sua condutividade. Consequentemente, menor será a corrente Foucault e maior será a tensão de desbalanceamento nos terminais da ponte de indutâncias.

Numa situação em que o cabo se encontre em estado de corrosão é ainda possível avaliar qual a tensão mecânica que o condutor pode suportar. Para tal é incorporada uma câmara com sensor CCD (charged coupled device) que faz o registo da imagem para que seja avaliada pelo conjunto dos dados guardados no sistema.

Através de uma recta ajustada de forma empírica, a qual depende apenas do material usado (aço ou alumínio), obtém-se a percentagem remanescente da secção original do cabo. Com este dado definido, consegue-se estimar também através de forma empírica a tensão mecânica máxima suportável pelo cabo.

O procedimento de avaliação das condições do condutor é mostrado na figura 4.

\subsection{IMPLEMENTAÇÃO UTILIZANDO UM CARRINHO DE LINHA VIVA}

Para executar a inspecção da linha de transmissão, o circuito mostrado na figura 3 é montando sobre um carrinho de linha activa, que pode utilizar tanto auto propulsão como ser 


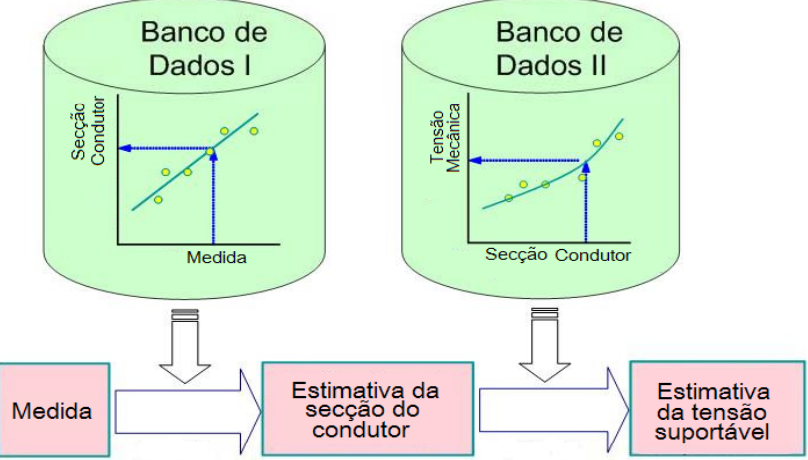

Figura 4 - Procedimento para estimar quantitativamente o estado de corrosão de um condutor

deslocado por um técnico devidamente treinado para o serviço em linha activa. As bobines são implementadas através de acopladores indutivos do tipo bipartido que suportam bitolas entre 160 e $810 \mathrm{~mm}^{2}$.
Além disso, a câmara CCD é posicionada próxima da bobine activa para registar visualmente as condições do condutor. Os detalhes do sistema podem ser vistos na figura 5 .

$\mathrm{O}$ peso do equipamento é de $50 \mathrm{~kg}$ e a velocidade aproximada de $10 \mathrm{~m} / \mathrm{min}$, sendo o ângulo máximo de catenária suportado de 20 .

Na versão com auto-propulsão, são adicionados $20 \mathrm{~kg}$ devido às baterias que conseguem realizar até $1000 \mathrm{~m}$ de inspecção sem recarregar.

Após percorrer a linha, o equipamento emite um relatório completo e referenciado com as condições do condutor, que associado às gravações da câmara CCD, identifica as secções críticas dos condutores. Para cabos ACSR é possível, inclusive, detectar separadamente a condição dos fios de alumínio e dos fios de aço que compõem o mesmo.

Um exemplo deste relatório pode ser visto na figura 6.

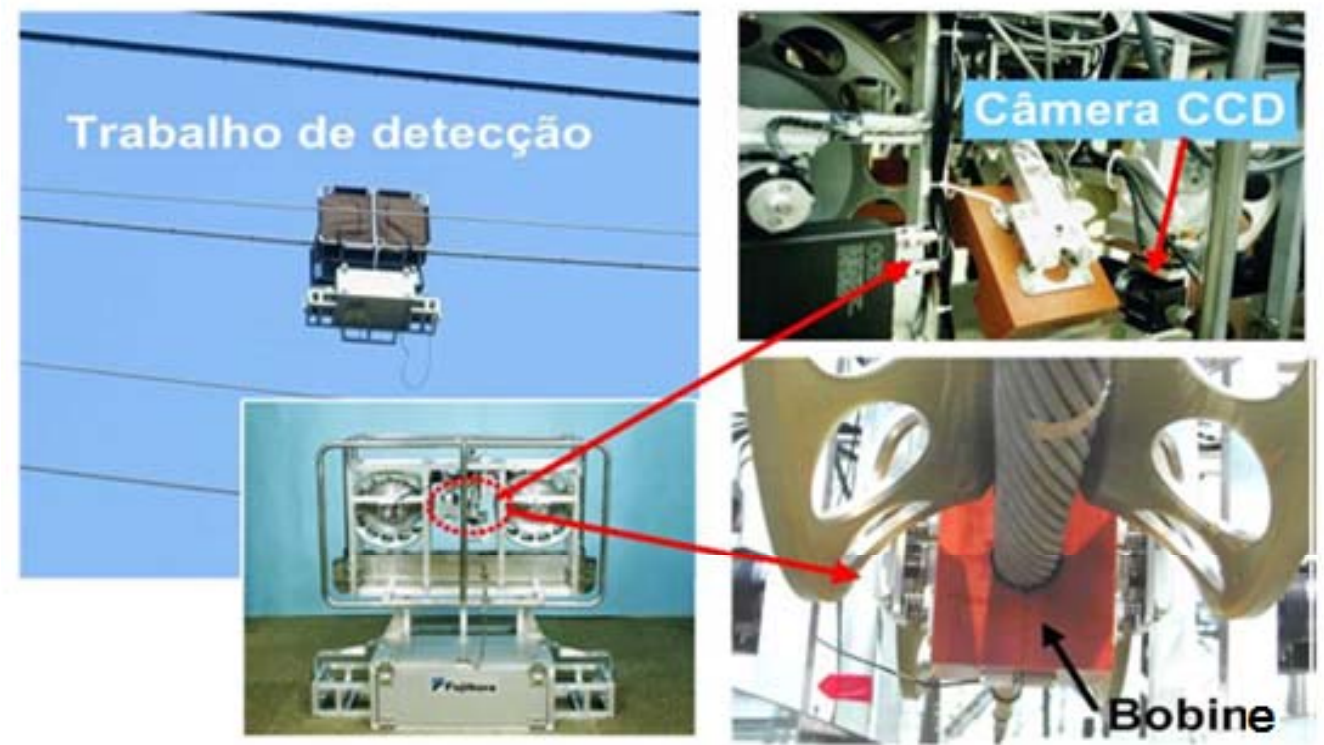

Figura 5 - Detalhes construtivos do sistema detector de corrosão

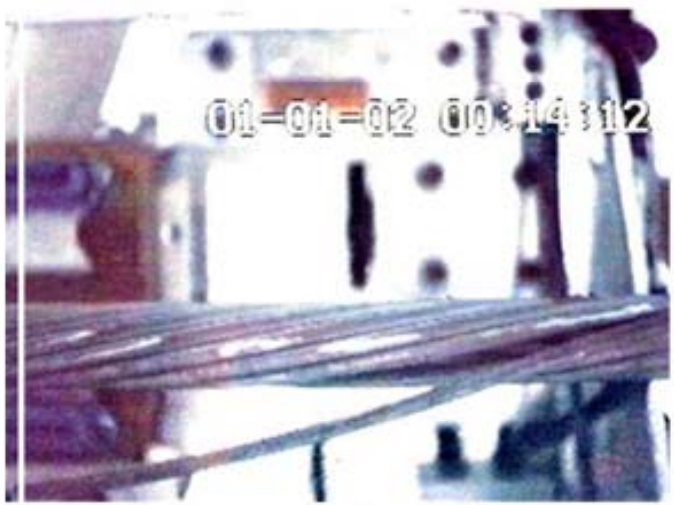

(a) Imagem do ponto de defeito

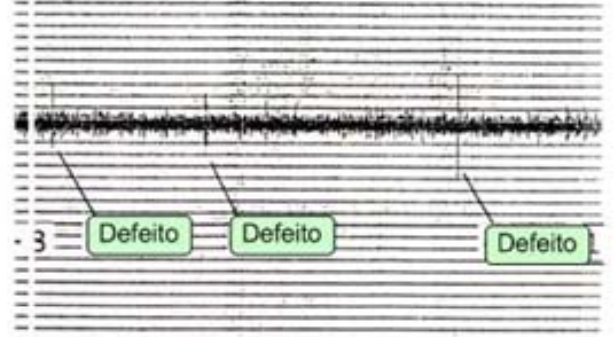

(b) Relatório referenciado indicando os pontos de defeito

Figura 6 - Informações fornecidas pelo sistema detector de corrosão 


\section{Aplicações no Âmbito da MANUtenção}

\subsection{MANUTENÇÃo CORRECTIVA}

As aplicações no âmbito da manutenção correctiva do localizador de defeitos por ondas viajantes são imediatas. Com uma configuração simples o sistema é capaz de localizar curto-circuitos defeitos fase-terra e identificar as seç̧ões afectadas com grande precisão e rapidez. Com uma incerteza menor que $\mathbf{3 0 0}$ metros, o defeito fica restrito a dois vãos na maior parte das linhas de transmissão existentes.

Isso significa que a fonte do defeito pode ser localizada com maior rapidez, muitas vezes numa simples inspecção visual a partir do solo. Essa informação mais precisa facilita o trabalho das equipas de campo, principalmente em áreas sujeitas a alagamento, regiões montanhosas ou de selva, já que é possível identificar antes mesmo da saída das equipas para o campo o melhor local de acesso ao ponto de defeito. Além de auxiliar na localização dum ponto de defeito que causou o desligamento da linha, o sistema também pode identificar fontes de defeitos intermitentes. Como as ondas viajantes são geradas sempre que há um transitório na linha, ocorrências de difícil localização como defeitos fase-terra causados por falhas em isoladores, presença de vegetação ou excrementos de pássaros podem ser restritas a uma área delimitada e estudada detalhadamente em menor tempo, gerando economia de tempo e recursos para as concessionárias.

\subsection{MANUTENÇÃo PREVENTIVA}

O detector de corrosão em cabos condutores tem aplicação voltada para a manutenção preventiva. Ao realizar uma inspecção aos condutores, é possível obter informações valiosas sobre o estado de conservação dos cabos.

Através dos dados fornecidos pelo equipamento, como secção de condutor remanescente e tensão mecânica suportável, torna-se relativamente fácil recalcular a carga máxima do sistema. Desta forma, através da restrição temporária da corrente máxima da linha para valores abaixo do nominal, evita-se um possível rompimento do condutor e os enormes transtornos que uma ocorrência deste tipo pode trazer. Também permite que as equipas de manutenção tenham tempo hábil para se preparar e mobilizar recursos para resolver o problema da maneira mais eficiente possível. Além disso, ao identificar secções específicas da linha com alto índice de corrosão mas sem perigo de rompimento, torna-se possível abordar o problema de forma preditiva, estudando soluções como substituição dos condutores por cabos resistentes à corrosão ou aplicação de produtos anticorrosão em novos cabos do mesmo tipo, de forma a realizar uma intervenção programada no sistema para a solução do problema.

\section{CONCLUSÕES}

A localização de defeitos por ondas viajantes e a detecção de corrosão são duas técnicas que pretendem disponibilizar informações quantitativas às equipas de manutenção.

Apesar de os seus princípios já serem conhecidos há muito tempo, apenas recentemente, através do desenvolvimento de novos materiais e uso de sistemas modernos como o GPS, foi possível desenvolver equipamentos que gerassem informações precisas sobre defeitos que ocorrem numa linha de transmissão.

O resultado é imediato na área de manutenção, já que uma localização precisa de defeitos traz uma maior eficácia, reduzindo o tempo no deslocamento da equipa e na identificação do defeito, permitindo a identificação de fontes intermitentes, um maior tempo para a solução do problema e a programação na realização dos serviços.

Isso traz benefícios directos tanto para as concessionárias como para as populações, já que a energia não distribuída engloba duas parcelas: o lucro cessante, que é o prejuízo da companhia pela energia não facturada e o custo social, o que a sociedade em geral perde quando há falta de energia.

Apesar de em Portugal não existir um estudo relacionado com as quebras de energia, em países como o Brasil alguns estudos apontam que o custo social é da ordem de 35 a 50 vezes o preço médio do $\mathrm{kWh}$ facturado, para regiões menos industrializadas, e de 50 a 100 vezes, para regiões mais industrializadas. 
Por isso, embora os equipamentos tradicionais se demonstrem eficazes no âmbito da protecção, torna-se necessária a aplicação de novas técnicas e equipamentos para disponibilizar informações quantitativas às equipas de manutenção, de forma a manter um sistema eléctrico seguro e confiável.

\section{Bibliografia}

[1] Regulamento da Qualidade de Serviço, ERSE - Entidade Reguladora dos Serviços Energéticos, Março 2006

[2] Motta, S. e Colosimo, E., Impactos da Manutenção e dos Custos da não Confiabilidade de Equipamentos sobre as Receitas de Serviços de Transmissão de Energia Eléctrica. Anais do XVII SNPTEE - Seminário Nacional de Produção e Transmissão de Energia Eléctrica

[3] Relatório do Comitê Nacional Brasileiro no B2 da CIGRÉ Conference Internationale dês Grands Réseaux Electrique a Haute Tension, Belo Horizonte, Outubro 2003

[4] REN - Rede Energética Nacional, disponível em www.ren.pt

[5] Esmo - 95 Proceedings, The Seventh International Conference on Transmission and Distribution Construction and Live Line Maintenance, October 29November 3, International Conference on Transmission and Distribution Construction and Live Line Maintenance, 1995, Ohio

[6] Documento técnico elaborado pelo Departamento de Gestão e Economia da Universidade da Madeira publicado em:

http://www.uma.pt/sbudria/Blackout_project_Jan09.pdf

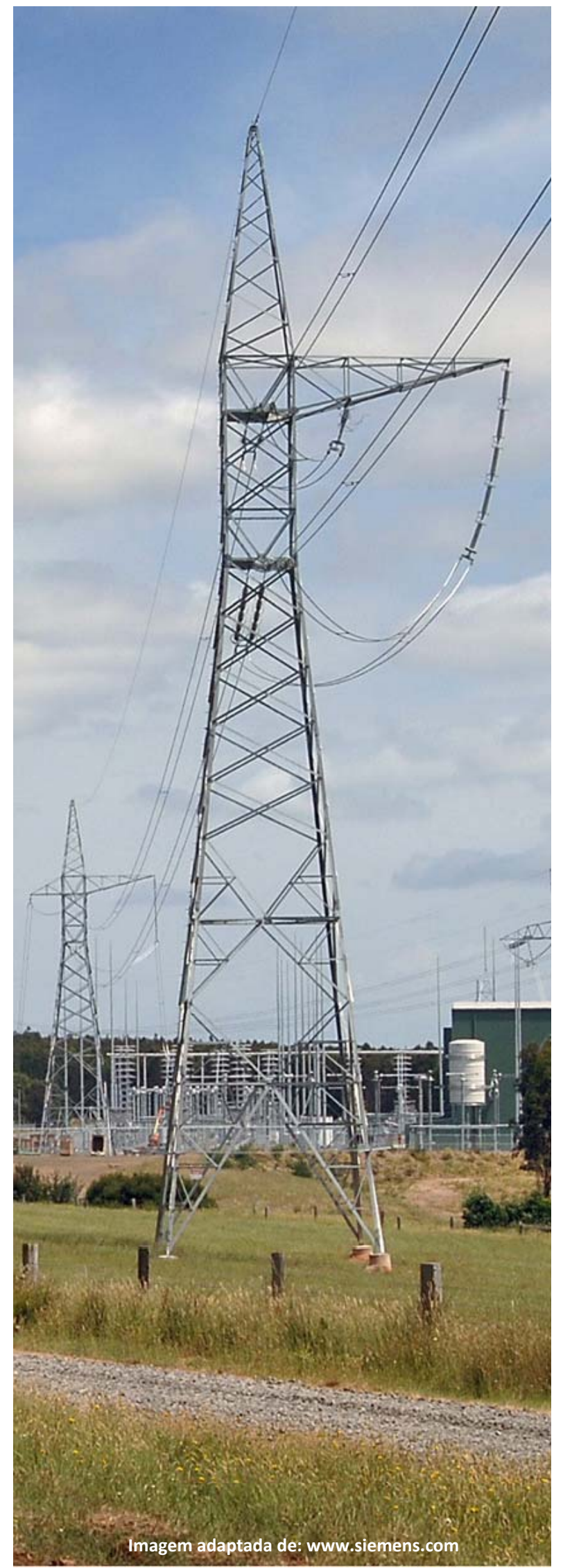

